\title{
ACOUSTIC EMISSION DETECTION \\ IN THE PRESENCE \\ OF HYDRAULIC NOISE
}

DECEMBER 1968

\section{AEC RESEARCH \& DEVELOPMENT REPORT}




\section{LEGAL NOTICE}

This report was prepared as an account of Government sponsored work. Neither the United States, nor the Commission, nor any person acting on behalf of the Commission:

A. Makes any warranty or representation, expressed or implied, with respect to the accuracy, completeness, or usefulness of the information contained in this report, or that the use of any information, apparatus, method, or process disclosed in this report may not infringe privately owned rights; or

B. Assumes any liabilities with respect to the use of, or for damages resulting from the use of any information, apparalus, method, or process disclosed in this report.

As used in the above, "person acting on behalf of the Commission" includes any employee or contractor of the Commission, or employee of such contractor, to the extent that such employee or con. tractor of the Commission, or employee of such contractor prepares, disseminates, or provides access to, any information pursuant to his emplayment or contract with the Commission, or his employment with such contractor.

\section{PACIFIC NORTHWEST LABORATORY}

RICHLAND, WASHINGTON

operated by

BATTELLE MEMORIAL INSTITUTE

for the

UNITED STATES ATOMIC ENERGY COMMISSION UNDER CONTRACT AT(45-1)-1830 
BNWL -933

UC-37, Instruments

\title{
ACOUSTIC EMISSION DETECTION IN THE PRESENCE \\ OF HYDRAULIC NOISE
}

\author{
By \\ P. H. Hutton \\ Nondestructive Testing Department \\ Systems and Electronics Division
}

December 1968

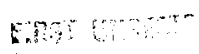

water

BATTELLE MEMORIAL INSTITUTE PACIFIC NORTHWEST LABORATORY RICHLAND, WASHINGTON 99352 
Printed in the United States of America Available from

Clearinghouse for Federal Scientific and Technical Information National Bureau of Standards, U.S. Department of Commerce Springfield, Virginia 22151

Price: Printed Copy $\$ 3.00$; Microfiche $\$ 0.65$ 


\title{
ACOUSTIC EMISSION DETECTION IN THE PRESENCE OF HYDRAULIC NOISE \\ P. H. Hutton
}

\begin{abstract}
When use of "acoustic emission" produced as metals deform and fracture is considered as a means of continuously monitoring the integrity of nuclear reactor pressure boundaries, segregation of emission data from background noise must be evaluated. Testing has been performed to demonstrate detection of acoustic emission in the presence of turbulent flow and cavitation hydraulic noise. The results show that an acoustic emission sensing system operating in the 1.5 to $2.5 \mathrm{MHz}$ frequency range with shear sensors is essentially insensitive to either turbulent flow or cavitation noise. At the same time, this system will detect acoustic emission signals clearly at a distance of at least $3 \mathrm{ft}$ from the signal source. Follow-on work is necessary to optimize the sensing technique, adapt it to routine field application, and establish the maximum distance at which an acoustic emission signal can be reliably detected.
\end{abstract}


, 


\section{TABLE OF CONTENTS}

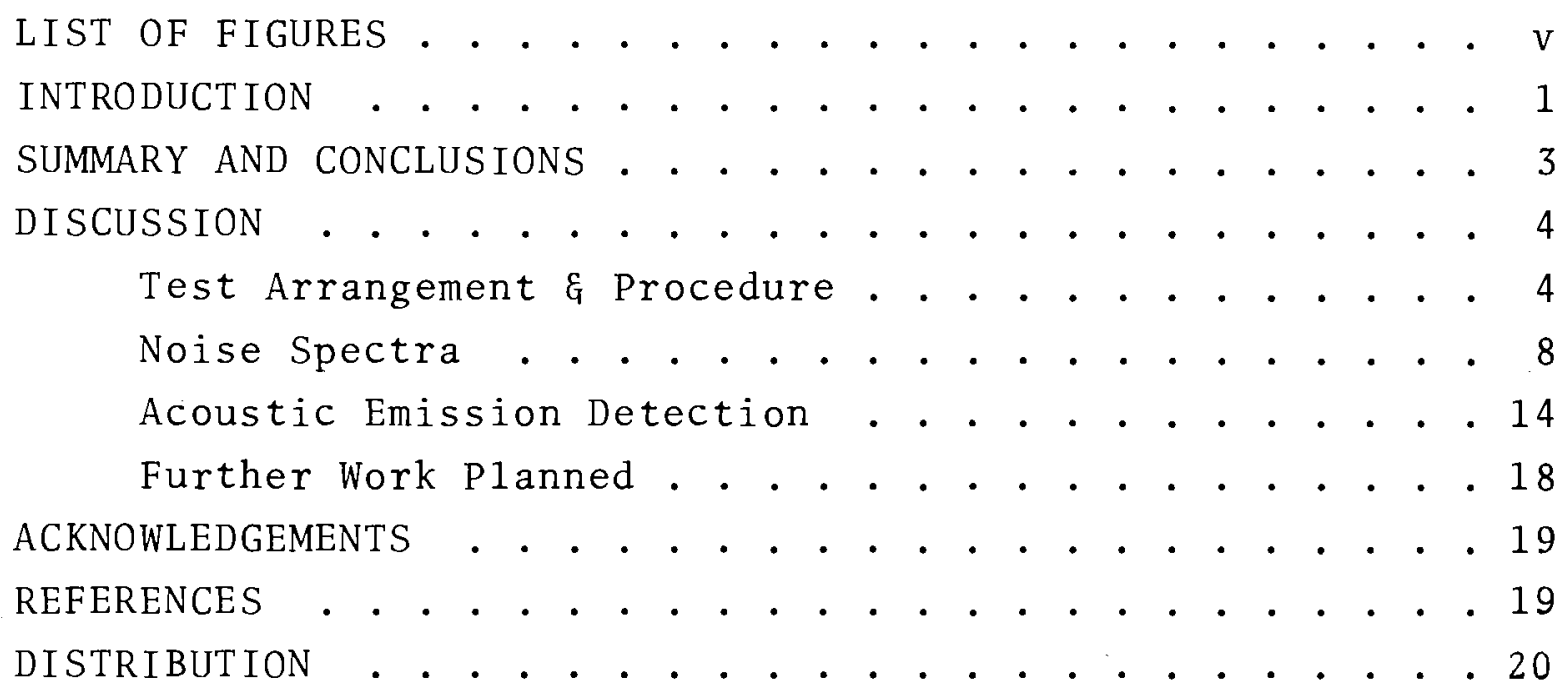

\section{LIST OF FIGURES}

1 Test Arrangement: Detection of Acoustic Emission in the Presence of Hydraulic Noise

2 Sketch of Test System: Detection of Acoustic Emission in the Presence of Hydraulic Noise

3 Hydraulic Noise Spectra: Turbulent Flow

4 Comparison of Noise Signal for Cavitation and Noncavitation Conditions

5 Hydraulic Noise Spectra: Turbulent Flow and Cavitation Conditions

6 Hydraulic Noise Spectra: Dresden I Nuclear Power Reactor

7 Acoustic Emission Signals Detected in the Presence of Hydraulic Noise-A

8 Acoustic Emission Signals Detected in the Presence of Hydraulic Noise-B 
$\checkmark$ 


\section{ACOUSTIC EMISSION DETECTION IN THE PRESENCE \\ OF HYDRAULIC NOISE \\ P. H. Hutton \\ INTRODUCTION}

A development program is in progress at the Pacific Northwest Laboratory operated by the Battelle Memorial Institute (Battelle-Northwest) for the purpose of utilizing the acoustic emission phenomenon for continuous integrity surveillance of nuclear reactor pressure boundaries. The program is sponsored by the USAEC's Division of Reactor Development and Technology.

Acoustic emission is a phenomenon arising from energy released as a solid material undergoes plastic deformation and fracture. Part of this energy is converted to elastic waves which propagate through the material and can be detected by high sensitivity sensors at the material surface. Therein lies the basis for utilizing this phenomenon to detect formation or growth of flaws in reactor pressure boundaries and other structures on a real-time, continuous basis.

A significant question concerning the application of acoustic emission is, "Can acoustic emission signals be segregated from the general system noise?" In the case of a nuclear reactor pressure system, the primary concern is with hydraulic flow and pump noise which might mask acoustic emission. Noise measurements made during May and June 1968 on the Commonwealth Edison Co.'s Dresden I nuclear power reactor indicated that hydraulic noise would not be a problem if acoustic emission could be detected using a frequency range of about $750 \mathrm{kHz}$ to $3 \mathrm{MHz}$. (1) The existence of acoustic emission signal components in this frequency range was confirmed in the laboratory. A logical next step was to combine acoustic emission and hydraulic 
noise to demonstrate the feasibility of segregating acoustic emission signals from the hydraulic noise. The purpose of this report is to discuss such a test and the results obtained. 


\section{SUMMARY AND CONCLUSIONS}

A $3 / 8$ in. thick, Type A-212-B carbon steel test specimen attached to an existing hydraulic test 1oop was used to investigate separation of acoustic emission signals from hydraulic background noise. The investigation involved centrifugal pump driven turbulent flow of water about $500{ }^{\circ} \mathrm{F}$ at velocities up to $30 \mathrm{ft} / \mathrm{sec}$ and cavitation generated by throttling a gate valve in the system. Cavitation produced extremely high noise levels below about $500 \mathrm{kHz}$-approximately 50 times that generated by turbulent flow alone. The resulting noise spectra were similar to those observed previously on a nuclear power reactor-Commonwealth Edison Co.'s Dresden I.

Three sensor arrangements were used for acoustic emission detection. One was a damped, longitudinal crystal that was surface mounted, and the other two were undamped shear crystals mounted on the edge of the plate and on the edge of a block attached to the plate surface. The shear sensors, with appropriate signal conditioning, detected acoustic emission clearly at a distance of about $3 \mathrm{ft}$ and were essentially unaffected by any of the hydraulic noise. The longitudinal surface mounted sensor showed identifiable response to acoustic emission in the presence of turbulent flow noise. However, cavitation noise seriously degraded reception of distinguishable acoustic emission signals. With the filter set low enough for good response to emission signals, cavitation noise obliterated the emission response. With the filter set high enough to control cavitation noise, the response to acoustic emission was also significant $1 y$ attenuated.

This test has demonstrated that clear detection of acoustic emission in the midst of hydraulic noise (even cavitation) is feasible by using specialized, mode selective sensors operating in the frequency range of 1.5 to $3 \mathrm{MHz}$ with appropriate signal conditioning electronics. 


\section{DISCUSSION}

Detection of acoustic emission from flaw growth in meta 1 structures during relatively noise-free operations such as hydrostatic testing of pressure vessels has been established as a feasible and useful technique. Extending the application to continuous surveillance of an assembly such as a reactor pressure system for detection of flaw growth during operation imposes significantly more demanding requirements. Included in this case are the necessity for sensors to function for periods of at least $1-1 / 2$ to 2 years in an environment of nuclear radiation and temperature in the 600 to $700^{\circ} \mathrm{F}$ range. Test work is being generated to confirm analytical conclusions that sensors are available which will withstand the radiation and high temperature environment. The other major requirement imposed for continuous surveillance of an operating system is to be able to detect acoustic emission signals in a clear,

sharp form in the midst of system background noise. The acoustic emission signals as sensed must be significantly above background noise for reliable detection and processing, and the wave front must be sharp to facilitate accurate source location by triangulation. A test has been performed to demonstrate that this latter requirement can be met as applied to nuclear reactor pressure systems; the purpose of this report is to discuss the test results.

\section{TEST ARRANGEMENT AND PROCEDURES}

In order to introduce known acoustic emission into a simulated reactor coolant system noise environment, a test specimen was attached to an existing hydraulic test 1oop. The 1oop at the point where the test specimen was attached consists of $2-5 / 8$ in. OD steel tubing. For the purpose of this test, flow velocities up to slightly over $30 \mathrm{ft} / \mathrm{sec}$ and fluid temperature 
of about $500^{\circ} \mathrm{F}$ were used. A gate valve located about $10 \mathrm{ft}$ upstream of the point where the specimen was attached was used to generate cavitation. The test specimen consisted of a $3 / 8$ in. thick plate of A-212-B carbon steel 40 in. long by 12 in. wide. Figure 1 shows the test arrangement. Eight inch long "fingers", $1 / 2$ and $3 / 4$ in. wide were cut in one end of the plate for use in generating acoustic emission. These were manually bent down and ultimately broken to produce emission signals. They are shown in the foreground of the right hand picture in Figure 1. All surface oxide and scale was removed from the plate in the vicinity of the root of the fingers to assure that true acoustic emission was produced. Sensors were located at the opposite end of the plate from the fingers. The test plate was attached to the hydraulic loop at a point between the sensors and emission source and 8 to 10 in. from the sensors. The plate was attached to the loop by two "U" bolts around the pipe and through the plate. General Electric Co. RTV-116 silicone rubber was used for acoustic coupling between the plate and pipe. Previous tests have shown this to be an efficient coupling agent. Also, a groove was cut in the plate to match the pipe radius to increase the contact surface and enhance acoustic transmission.

The test system is outlined in Figure 2. The output from the data sensors located at the opposite end of the plate from the bend tabs was fed, two channels at a time, through conditioning electronics and into a dual beam oscilloscope. A single sensor was located very near the root of the bend tabs, and its output was fed into the external trigger circuit of the oscilloscope. With this arrangement and the oscilloscope operated in the single sweep external trigger mode, an acoustic emission signal triggers the oscilloscope as it passed the first sensor, and the complete response of the data sensors to this signal then appears on the screen at a position determined 

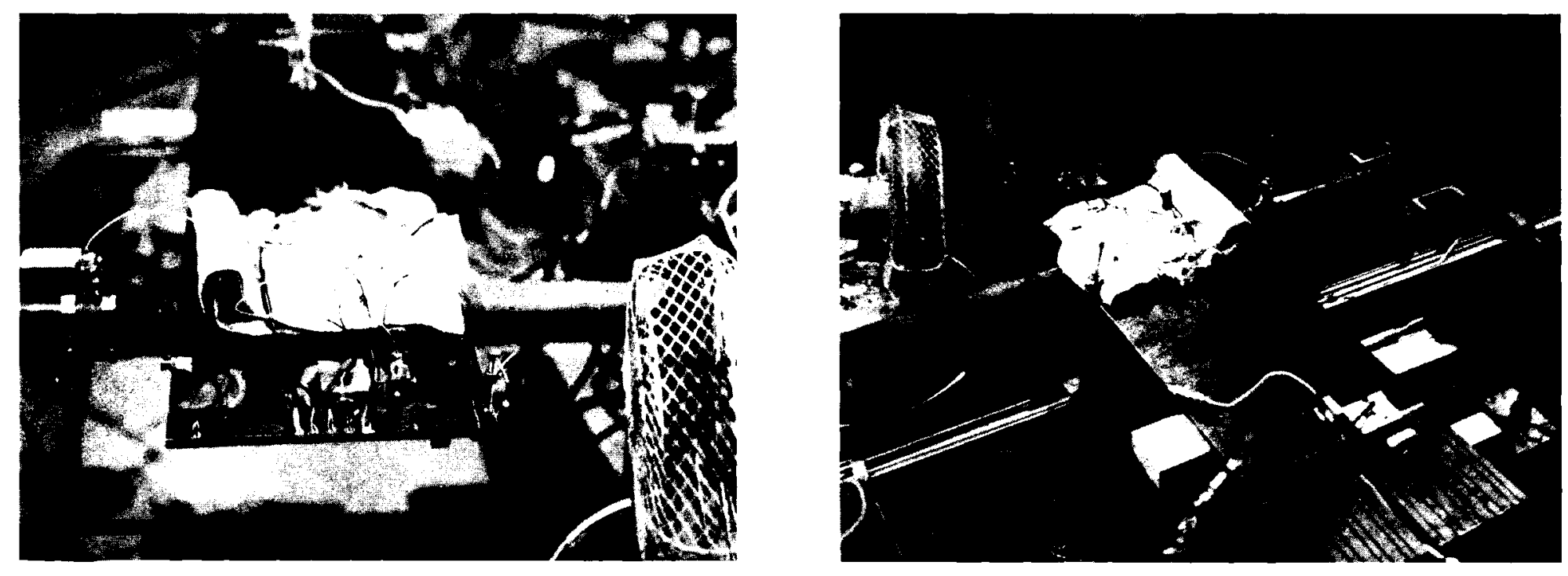

Neg $0683998-7$

FIGURE 1. Test Arrangement: Detection of Acoustic Emission in the Presence of Hydraulic Noise 


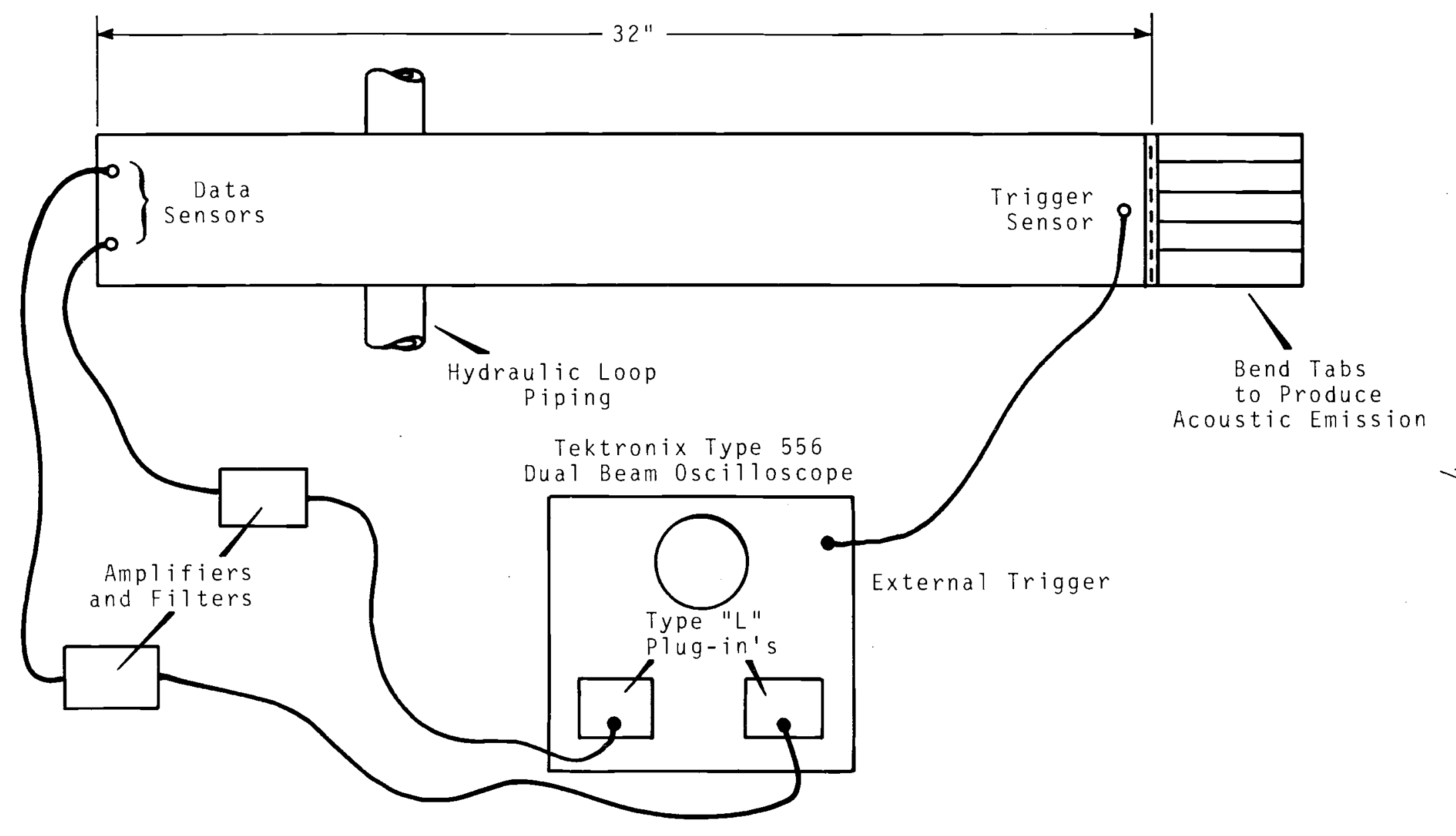

Neg 0683998-8 
by sweep rate. The data images on the screen were recorded photographically. Data signals viewed in the above manner can be positively identified as being acoustic emission originating at the root of the bend tabs.

Noise spectra were measured at two points: one on the pipe adjacent to the test plate and the other on the test plate. In both cases, the sensors were damped, longitudinal, $1 \mathrm{MHz}$, PZT-5A transducers mounted on the surface. (It should be noted that the designation "I MHz" derives from ultrasonic work wherein it describes the cut of the crystal and its optimum response frequency as a sender. It does not define the upper limit of detection when using the crystal in a damped configuration as a receiver.) The output from these sensors was amplified and fed into a Tektronix 1 L 5 spectrum analyzer with the resulting spectrum analysis displayed on a Tektronix Type 549 storage oscilloscope. The information was then recorded photographically.

\section{NOISE SPECTRA}

The noise spectra produced on the pipe and on the test specimen by turbulent flow of 475 to $500^{\circ} \mathrm{F}$ water in the pipe at approximately $30 \mathrm{ft} / \mathrm{sec}$ are shown in Figure 3. As the upper photos show, the major noise field lies below $200 \mathrm{kHz}$. Since the analyzer is prone to become unstable when overloaded on the input, the noise data were analyzed a second time with a $300 \mathrm{kHz}$ high-pass filter in the circuit. These spectra are shown in the bottom photos and agree well with the broader band analyses above the filter point. Gain between the transducers and the analyzer was limited to $10^{3}$ for spectral measurements in order to minimize analyzer overload. Comparison of the spectra from the pipe and the test plate show that acoustic coupling 

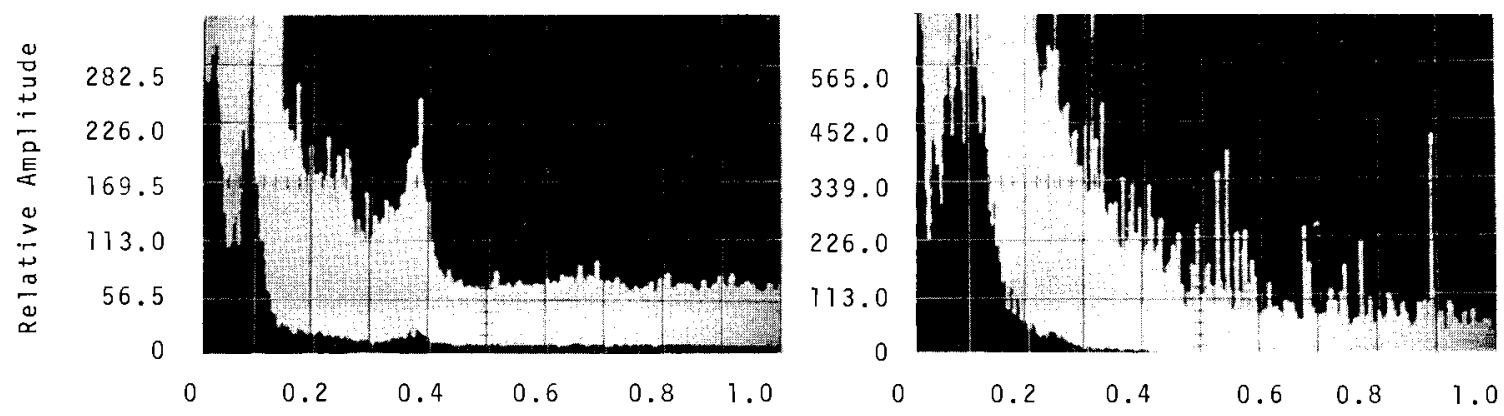

Frequency - $1 \mathrm{~Hz}$

$20 \mathrm{kHz}$. Hi-Pass Filter
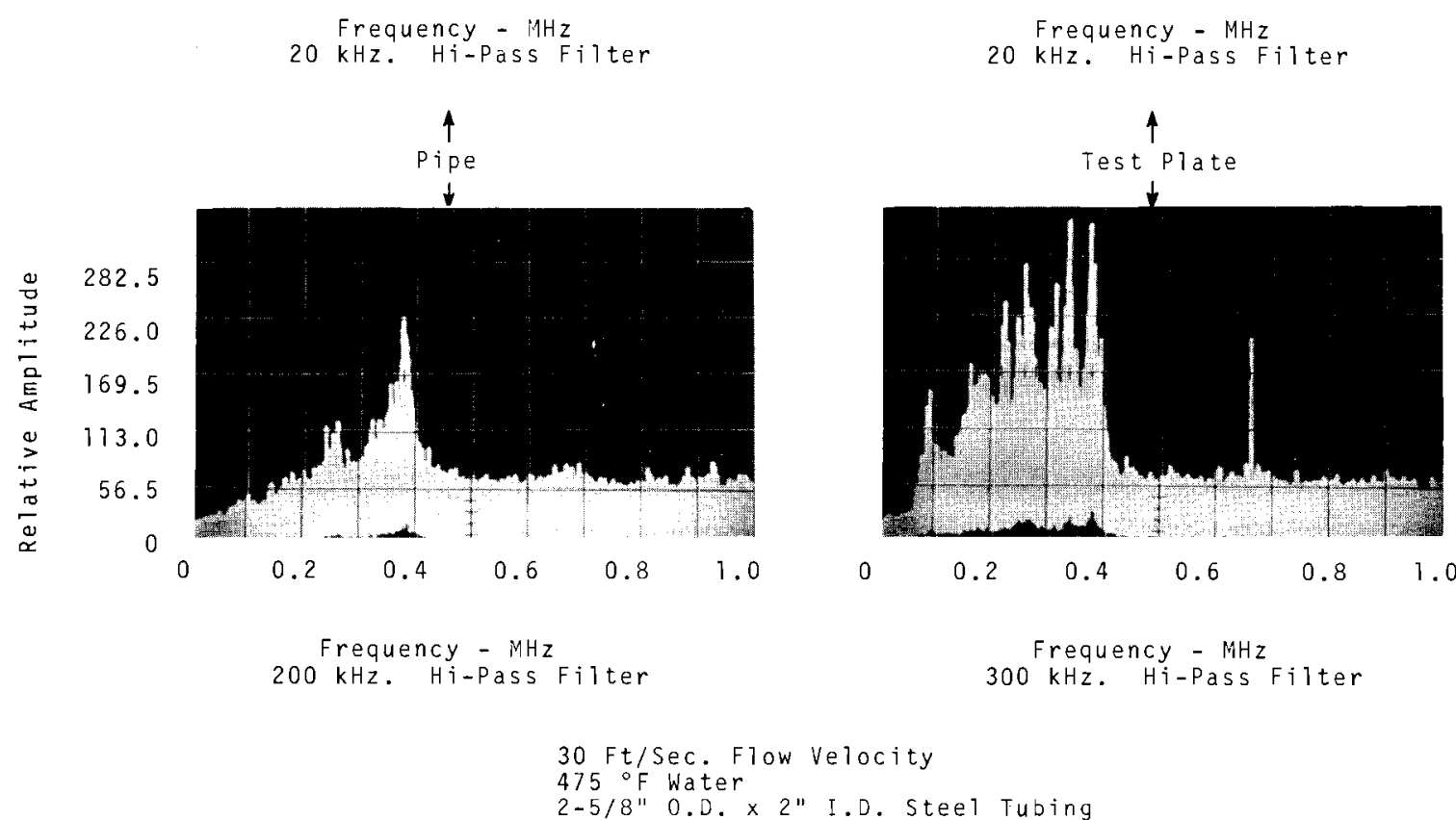

Neg 0683998-1

FIGURE 3. Hydraulic Noise Spectra: Turbulent Flow 
was quite good. In fact, the characteristics of the plate appeared to reinforce the hydraulic noise particularly in the lower frequencies.

Introduction of cavitation produced a nominal factor of 50 increase in noise intensity compared to turbulent flow alone. This is illustrated in Figure 4 which shows a vidio trace of the noise signals produced in the test specimen for both conditions. These traces were taken directly from the transducer with no amplifiers or filters between it and the oscilloscope. The greatest increase in noise level produced by cavitation was in the frequency region below $500 \mathrm{kHz}$. Spectra comparisons are given in Figure 5. With the onset of cavitation, the increase in low frequency noise was so severe that the signal had to be filtered at $500 \mathrm{kHz}$ high-pass with a $24 \mathrm{~dB} /$ octave filter in order to prevent instability in the analyzer. Although the major increase in noise produced by cavitation was in the lower frequencies, it also generated a significant increase in the spectrum level to about $800 \mathrm{kHz}$.

Information on the spectral content of hydraulic noise observed at the Dresden I nuclear power reactor (1) is reproduced in Figure 6 for comparison purposes. In general, the spectral distribution is very similar to that produced in the test arrangement. The spectrum shown in the bottom photo can only be assumed to originate from cavitation, but it compares quite closely to that from known cavitation shown in the lower left photo in Figure 5. Some differences in absolute indicated level between the on-reactor and the test conditions are attributable to differences in lead length between the transducers and preamplifier, and overall lead lengths from transducer to analyzer.

Both on-reactor data and test loop data indicate that hydraulic noise including that generated by cavitation is primarily below $1 \mathrm{MHz}$ in spectral content. 
Turbulent Flow - No Cavitation

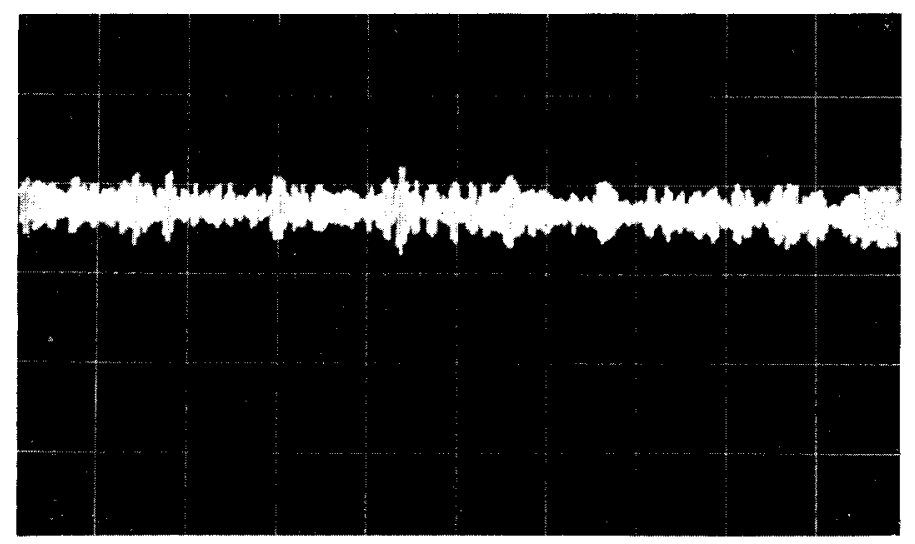

Vertical: 0.005 Volts $/ \mathrm{cm}$ Horizontal: $0.001 \mathrm{Sec} / \mathrm{cm}$

Turbulent Flow - With Cavitation

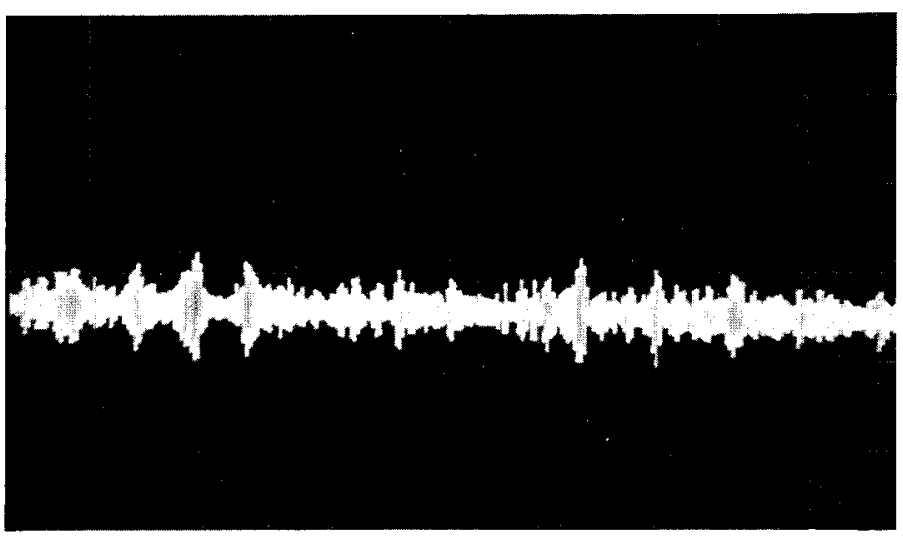

Vertical: 0.2 Volts/cm

Horizontal: $0.001 \mathrm{Sec} / \mathrm{cm}$

1.0 MHz. Longitudinal Transducer, Surface Mounted on the Specimen. No Filter and no Amplification Between Sensor and Scope.

Neg $0683998-6$

FIGURE 4. Comparison of Noise Signal for Cavitation and Noncavitation Conditions 

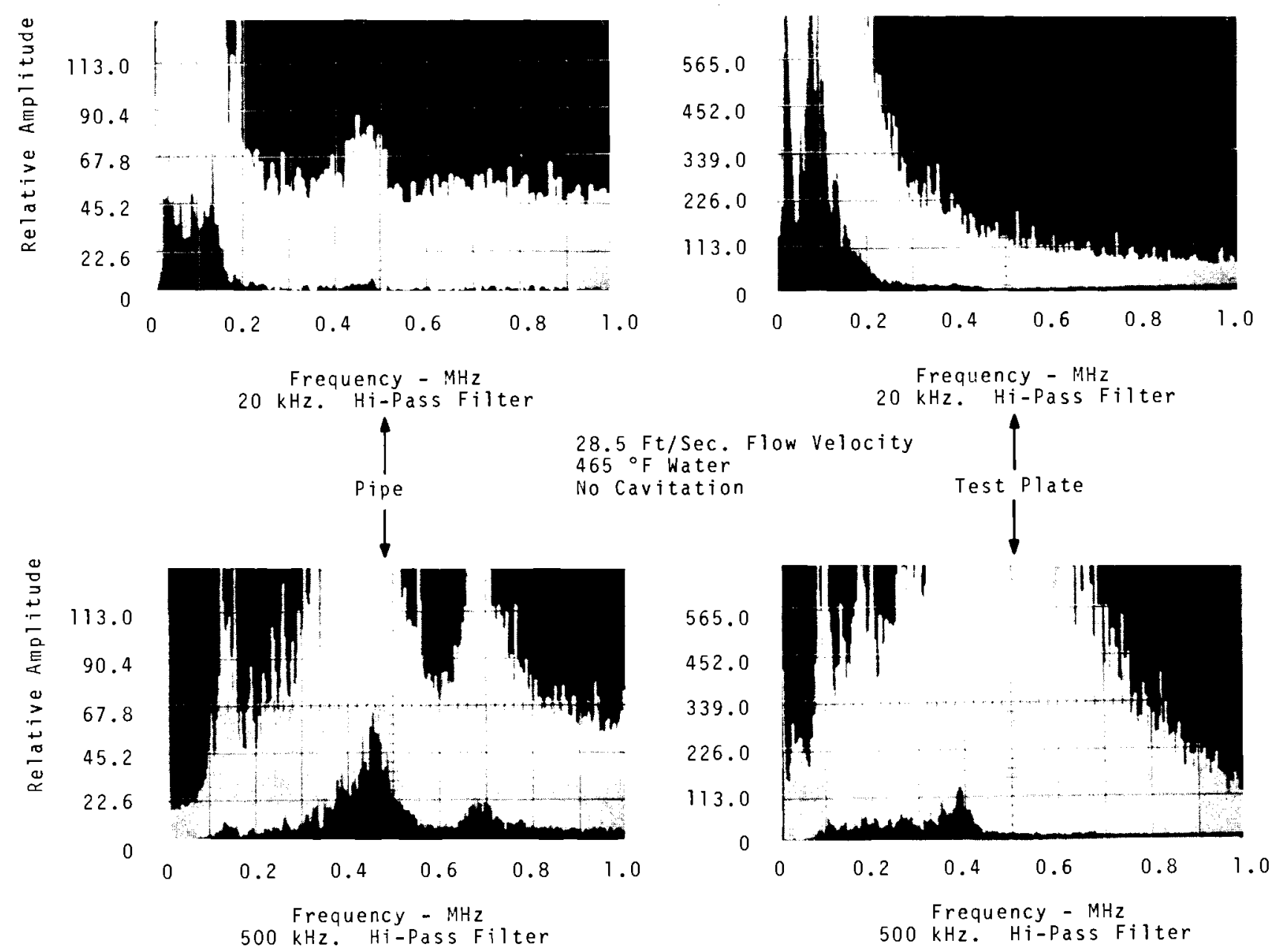

$20 \mathrm{Ft} / \mathrm{Sec}$. Flow Velocity
$505 \mathrm{~F}$ Water

Cavitation

Neg $0683998-5$

FIGURE 5. Hydraulic Noise Spectra: Turbuzent Flow 

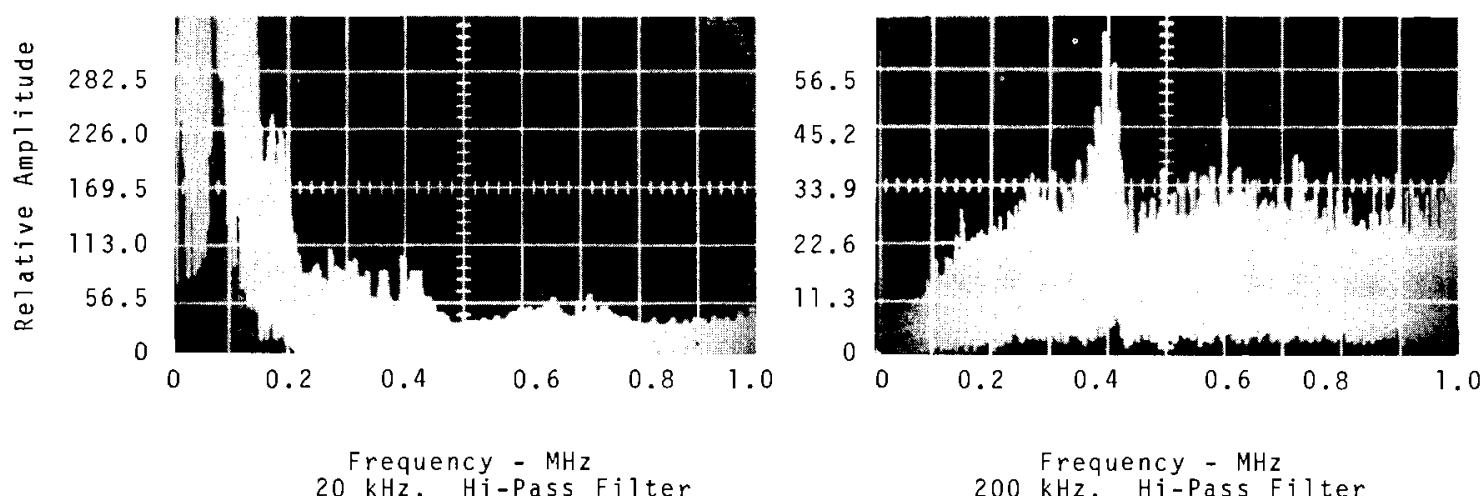

$20 \mathrm{kHz}$. Hi-Pass Filter

Frequency - MHz
$200 \mathrm{kHz}$. Hi-Pass Filter

$25 \mathrm{Ft} / \mathrm{Sec}$. Flow Velocity

$500^{\circ} \mathrm{F}$ water

Turbulent Flow

22 " West Recirculation lleader

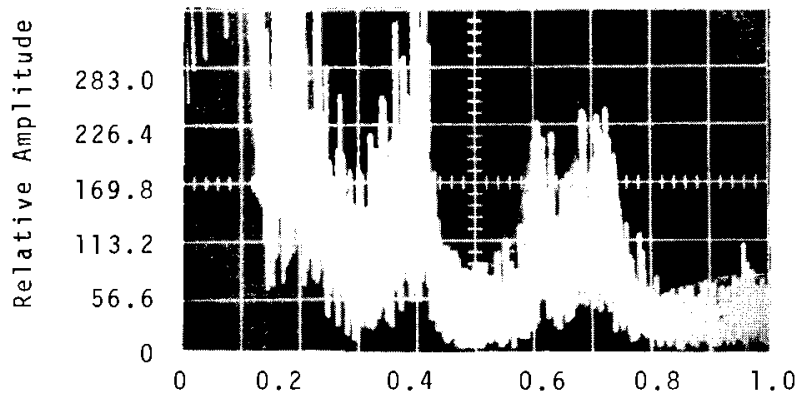

Frequency - $\mathrm{MHz}$

$20 \mathrm{kHz}$. Hi-Pass Filter

6" By-Pass, "D" Secondary Steam Generator

High Flow-Main Valve Throttled

Probable Cavitation

$400{ }^{\circ} \mathrm{F}$ water

Neg $0683998-2$

FIGURE 6. Hydraulic Noise Spectra: Dresden I

Nuclear Power Reactor 


\section{ACOUSTIC EMISSION DETECTION}

The main objective of this test was to demonstrate whether or not acoustic emission signals could be detected with clarity in the presence of hydraulic noise. The foregoing discussion has described the conditions under which the test was made. Figures 7 and 8 present the results of efforts to detect known acoustic emission at a distance of 32 in. in a hydraulic noise environment with four different detection systems. Acoustic emission was produced by slowly bending one of the "fingers" on the test plate until an emission event was generated to trigger the oscilloscope. The response of the selected data sensors to the same emission was recorded photographical1y.

The same detection arrangement was used for the top trace in all photographs to provide a correlation reference. This consisted of $2.2 \mathrm{MHz}$ shear transducer mounted on the edge of the plate with the sensor output routed through a 1.7 to 2.5 $\mathrm{MHz}$ narrow band amplifier which provided a gain of $1.5 \times 10^{4}$. The oscilloscope sweep rate used was $100 \mu \mathrm{sec} / \mathrm{cm}$. With a distance of about 31 in. between the trigger sensor and data sensors, the time delay for signal propagation should be:

$$
\frac{31 \text { in. } \times 10^{6}(\text { usec/sec })}{\left.13 \times 10^{4} \text { in. } / \text { sec (shear velocity in stee } 1\right)}=238 \mu \mathrm{sec}
$$

The data traces agree very closely with this value.

The bottom trace of the two top photographs of Figure 7 shows the response of a $1.7 \mathrm{MHz}$ shear sensor mounted on the edge of the plate with the signal conditioned by a broadband amplifier $\left(30 \mathrm{kHz}\right.$ to $3 \mathrm{MHz}$ ) with $10^{4}$ gain and a 1.2 to $2.0 \mathrm{MHz}$ band pass filter. The bottom trace in the bottom photographs of Figure 7 shows the response of an identical system only the sensor is mounted on the edge of a steel block cemented to the surface of the plate. 


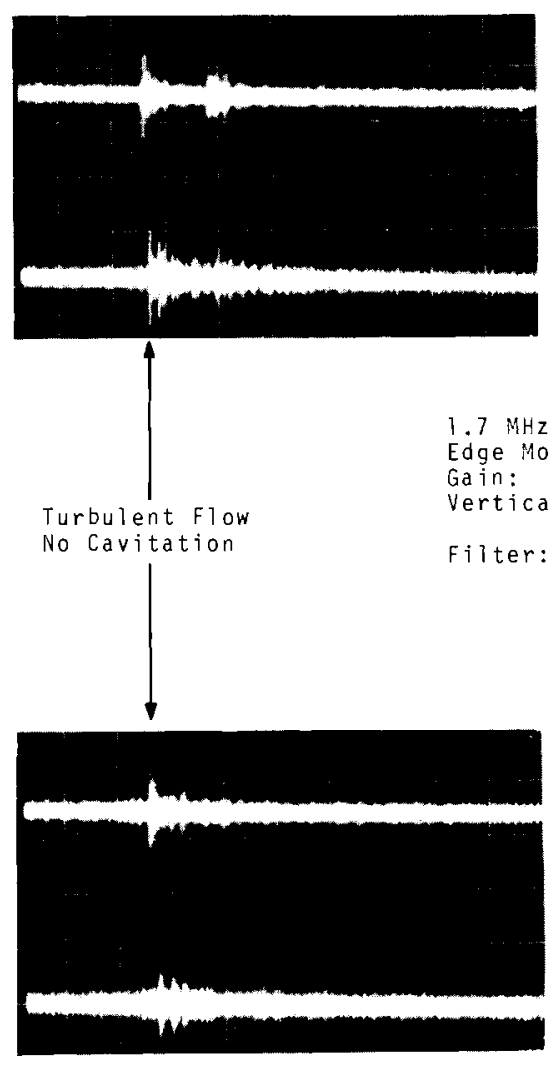

Bottom Trace

$1.7 \mathrm{MHz}$. Shear Sensor

Edge Mounted on Specimen

Gain: 104

Right - 1.0 Volts/cm

$1.2-2.0 \mathrm{MHz}$. Band Pass
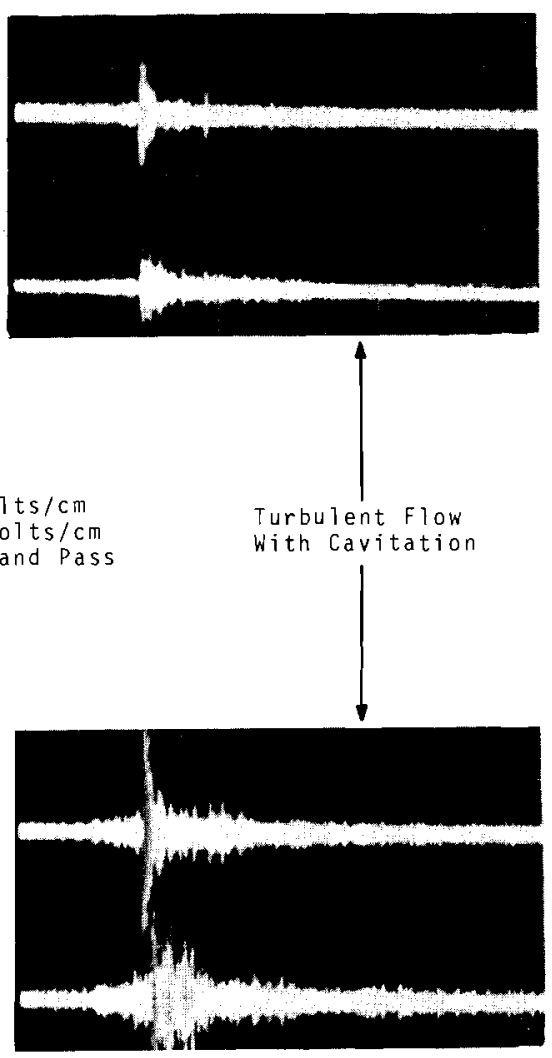

Bottom Trace

1.7 $\mathrm{MHz}$. Shear Sensor

Edge Mounted to Block

On Specimen Surface

Gain: 104

Vertical: 0.5 Volts $/ \mathrm{cm}$

Filter: 1.2-2.0 MHz. Band Pass

A11 Photos:

$\frac{\text { Top Trace }}{2.2 \mathrm{MHz}}$

Narrow Band Ampl fier, $1.7-2,5 \mathrm{MH}$

Gain: $1.5 \times 104$, Vertical: 2.0 Volts $/ \mathrm{cm}$

Sweep Rate $100 \mathrm{Hsec/cm}$

Neg $0683998-4$

FIGURE 7. Acoustic Emission Signals Detected in the Presence of Hydraulic Noise-A 

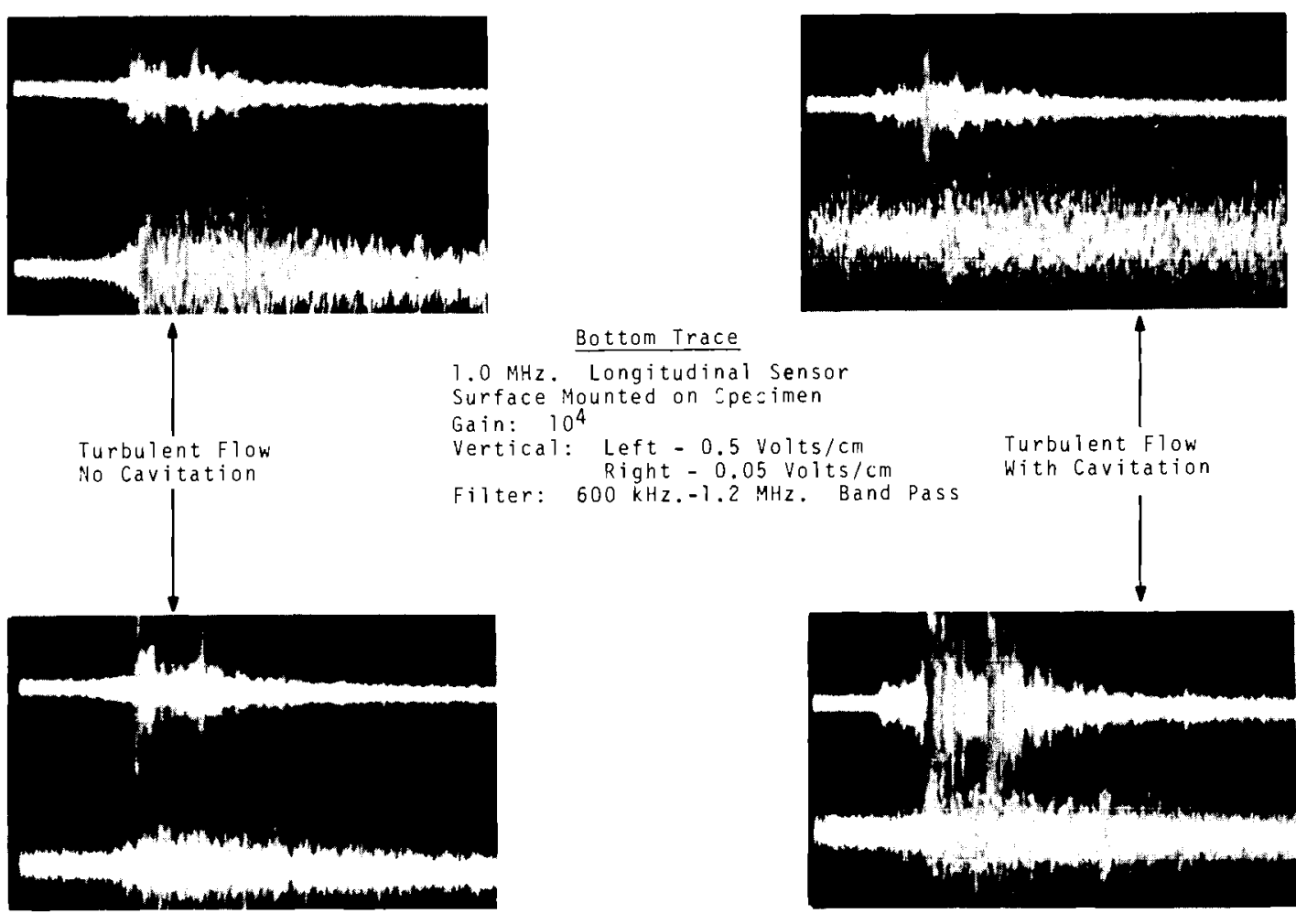

Bottom Trace

MHz. Longitudinal Sensor Surface Mounted on Spesimen Gain: $10^{4}$

Vertical: Left -0.5 Volts/cm Filter: $600 \mathrm{kHz} .-1.2 \mathrm{MHz}$. Band pass

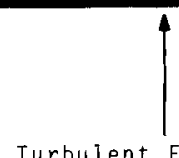

Turbuient $\mathrm{Flow}$ with Cavitation
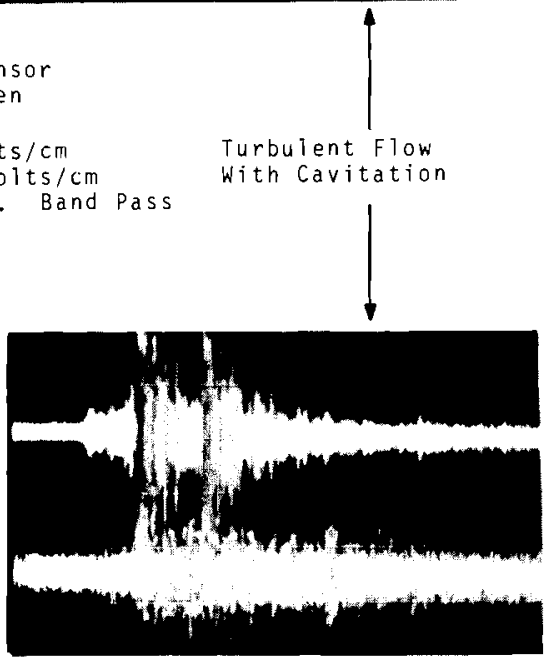

\section{Bottom Trace}

1.O MHz, Longitudinal Sensor Surface Mounted on Specimen Gain: $10^{4}$

Vertical: Left -0.2 Volts/cm

Right - $0.05 \mathrm{Vol} \mathrm{ts} / \mathrm{cm}$

Filter: $900 \mathrm{kHz} .-1.2 \mathrm{MHz}$. Band Pass

A11 Photos: Top Trace

$2.2 \mathrm{MHz}$. Shear Sensor Edge Mounted on Specimen

Narrow Band Amplifier, 1.7-2.0 Volts/cm

Eain: $1.5 \times 10^{4}$, Vertical: $2.0 \mathrm{Volts} / \mathrm{cm}$

Sweep Rate $100 \mathrm{usec} / \mathrm{cm}$

Neg $0683998-3$

FIGURE 8. Acoustic Emission Signals Detected in the Presence of Hydraulic Noise-B 
The bottom trace in all photographs in Figure 8 shows emission signals as detected by a $1 \mathrm{MHz}$ longitudinal sensor with the crystal damped and mounted on the plate surface. The sensor output is fed into a broadband amplifier $(30 \mathrm{kHz}$ to $3 \mathrm{MHz})$ for a gain of $10^{4}$ and filtered $600 \mathrm{kHz}$ to $1.2 \mathrm{MHz}$ in one case and $900 \mathrm{kHz}$ to $1.2 \mathrm{MHz}$ in the other.

In summary, the significant features of the acoustic emission detection data are:

1. Detection of acoustic emission above about $1.5 \mathrm{MHz}$ appears to be unaffected by hydraulic noise or even cavitation. Detection in this range is not felt to be a limitation. Recent investigations of the emission signal per se indicated that all of the emission, at least from steel, are sharp rise transients that can produce response in transducers in excess of $30 \mathrm{MHz}$.

2. The edge mounted shear wave sensor produces a much sharper and shorter response to acoustic emission than does the surface mounted longitudinal sensors. This is significant to detection resolution and to source location accuracy.

3. The surface mounted longitudinal sensor is not suitable for use with cavitation noise present. Although the crystal cut is $1 \mathrm{MHz}$, its major response is in a radial mode at about $350 \mathrm{kHz}$.

4. The quality of response obtained from edge mounted shear sensors on a block attached to the specimen surfaces demonstrates one way of applying these sensors on a practical basis to existing structures. The response is definitely not optimum, however, and better techniques are currently being sought. 


\section{FURTHER WORK PLANNED}

Additional development work is needed as a follow-up to the results of this test. There is a need to optimize the shear wave detection technique. Although the results obtained with the sensors used in this test are superior to those obtained with other techniques, they are not optimized. Further attention to mounting angle and bonding methods offers the opportunity to increase the signal-to-noise ratio and to sharpen the wave front by rejecting essentially al1 longitudinal waves.

Work is also needed to better adapt the shear sensing technique to practical application in the field. Mounting a shear sensor to the edge of a plate on the specimen surface produces a useable signal, but it is marginal for general application. Both signal-to-noise ratio and signal sharpness are compromised with this approach. Making a small depression in the metal surface in which to mount the sensors offers a distinct possibility of providing a feasible solution. Mounting a shear cube on the specimen surface does not appear to provide a solution. Laboratory tests indicate that in order to attain necessary sensitivity, the fundamental frequency of the transducer drops into the hydraulic noise range. These approaches are being investigated further.

A very important point to be resolved is the question of reliable detection distance using shear transducers. The magnitude of the detected signal at 32 in. in this test would indicate that a range of at least $10 \mathrm{ft}$ should be attainable, but this needs to be experimentally confirmed. Hopefully, a range considerably greater than $10 \mathrm{ft}$ can be achieved. 


\section{ACKNOWLEDGEMENTS}

The author wishes to gratefully acknowledge the assistance provided by Douglas United Nuclear, Inc. in conducting this test. The hydraulic test loop used is part of their facilities, and they provided personnel to operate the 100 .

\section{REFERENCES}

1. P. H. Hutton. Nuclear Reactor System Noise Analysis, Dresden I Reactor, Commonwealth Edison Co., BNWL-867. Pacific Northwest Laboratory, Richland, Washington, september 1968. 



\section{DISTRIBUTION}

No. of Copies

OFFSITE

1 AEC Chicago Patent Group

G. H. Lee

4 AEC Division of Reactor Development and Technology

E. H. Davidson, Engr \& Test

R. R. Newton, RDT (3)

270 AEC Division of Technical Information Extension

$1 \quad$ Battelle Memorial Institute

R. J. Eiber

2 Commonwealth Edison Company

E. C. Bailey

W. I. Kiedaisch

1 Atomic Energy of Canada, Ltd.

M. M. Gupta

$1 \quad$ Phillips Petroleum Co., NRTS

D. L. Parry

ONSITE-HANFORD

$1 \quad$ AEC Chicago Patent Group

R. K. Sharp (Rich1 and)

3 AEC RDT Site Representative

P. G. Holsted (2)

J. B. Kitchen

1 AEC Richland Operations Office

C. L. Robinson

3 Battelle Memorial Institute 
No. of

Copies

5 Douglas United Nuclear Inc.

R. E. Dunn

D. L. Hovorka

R. S. Peterson

R. J. Robinson

DUN File

33 Batte11e Northwest

C. A. Bennett

R. L. Brown, Jr.

S. H. Bush

J. H. Cox

K. O. Creek

G. J. Dau

J. W. He1m

P. H. Hutton (10)

W. D. Jolly

R. L. Knecht

R. N. Ord

H. N. Pedersen

C. B. Shaw

J. C. Spanner

J. C. Tobin

D. C. Worlton

FFTF Library - D. D. Taylor

Technical Information (5)

Technical Publications (2) 